\title{
Determination of hormonal combination for increased multiplication of tissue culture potato plantlets
}

\author{
F. Nuwagira ${ }^{1,3}$, S.B. Mukasa ${ }^{1}$, W.W. Wagoire ${ }^{2}$, P. Namugga ${ }^{3}$, I.N. Kashaija ${ }^{3}$ and A. Barekye ${ }^{3}$ \\ ${ }^{1}$ Department of Agricultural Production, Makerere University, P. O. Box 7062, Kampala, Uganda \\ ${ }^{2}$ Buginyanya Zonal Agricultural Research and Development Institute, P. O. Box 1356, Mbale, Uganda \\ ${ }^{3}$ Kachwekano Zonal Agricultural Research and Development Institute, P. O. Box 421, Kabale, Uganda
}

Author for correspondence: kharlfn@gmail.com

\begin{abstract}
Use of plant growth hormones either singly or in combination is vital for rapid multiplication of virus-free in-vitro potato (Solanum tuberosum $\mathrm{L}$.) plantlets for the production of clean seed potato. This study was carried out at Kachwekano Zonal Agricultural Research and Development Institute, Kabale district in south-western Uganda to identify a suitable hormonal combination and optimum concentrations for production of a high number of In-vitro plantlets for three farmer-preferred varieties Kachpot-1, Kinigi, and Victoria. Eight hormonal combinations were formulated and tested using a completely randomized design with three replicates in the tissue culture laboratory. Ten shoot tips from in-vitro raised plantlets were excised and transferred to each of these hormonal combinations. The effect of hormonal combinations was variety dependant. N3 produced the highest mean number of nodes (6.42), buds (4.32) and tallest plantlets (7.38) for Kinigi. N2 produced the highest number of buds in Kachpot 1. N4 produced the tallest plantlets (7.19), highest mean number of buds (5.88) and nodes (7.66) for Victoria. Therefore, N3, N2 and N4 should be used for rapid In-vitro propagation of Kinigi, Kachpot 1 and Victoria respectively.
\end{abstract}

Key words: In-vitro propagation, Solanum tuberosum

\section{Introduction}

Potato (Solanum tuberosum L.) is an annual crop belonging to the family Solanaceae and genus Solanum. Potato is a crop of global importance, ranking as the fourth most important food crop in the world after wheat, rice and maize, planted on 20 million ha in the world in 2005 (FAO,
2007. In Uganda, potato is mainly grown in the higher altitude areas $(>1500 \mathrm{~m}$ above sea level), where it serves as the main source of income. The areas include the Kigezi highland districts of Kabale and Kisoro in the southwest, Mbale and Kapchorwa districts on the slopes of Mount Elgon in the eastern and Nebbi district in the northern region. About $40 \%$ 
of the national harvest comes from the intensely farmed Kabale highlands (Ferris et al., 2001). Potatoes in these regions are grown mainly by small scale farmers. These farmers use conventional means to propagate potato through the use of tubers. This propagation is characterised by low multiplication ratios that ranges from 1:4 to 1:15 (Rabbani et al., 2001). Because of this low rate of multiplication, it takes many years to generate large quantities of seed to meet the demand of the seed potato industry.

Several methods have the capacity to greatly improve the rate of seed potato production; such methods include tissue culture and aeroponics technologies (Molitor et al., 1999; Ritter et al., 2001). Tissue culture is an excellent technology that can allow rapid multiplication of potato. Micro-propagated potatoes establish more quickly, grow more vigorously and produce higher yield than those propagated by conventional means (Mahmoud, 2006).

Several researchers have reported the use of MS medium, without hormones during proliferation stage but the growth was slow ( Yousef et al., 1997; Badon and Chauhan, 2010). Addition of growth regulators to the culture media has been reported to improve the number, growth and development of shoots (Ahmed et al., 1993; Rabban et al., 2001), though they are genotype dependant. The use of higher concentrations of $\mathrm{GA}_{3}$ supplemented with NAA and Vitamins has been reported to increase the number of nodes (Miller et al., 1985; Yousef et al., 1997). Rabbani et al. (2001) recommended the use of higher concentrations of $\mathrm{GA}_{3}$, supplemented with other phytohormones like BAP and NAA, and vitamins in order to increase the multiplication capacity of potato. In Uganda, the use of tissue culture is a new technique in seed potato production, therefore, appropriate media composition for rapid multiplication of potato tissue culture plantlets has not been optimised. Thus, the objective of this study was to optimize hormonal combinations for increased multiplication of tissue culture potato plantlets.

\section{Materials and methods}

This study was carried out in the tissue culture laboratory at Kachwekano Zonal Agricultural and Research Development Institute (KaZARDI) in Kabale district, southwestern Uganda. Three popularly grown and farmer-preferred varieties, namely Victoria, Kachpot1 and Kinigi obtained from KaZARDI were used in this study. Mini-tubers, previously harvested from the aeroponics culture, were used as the starting plant materials. The sprouted mini-tubers were planted in the wooden boxes containing moist sterilised soil in a screen-house to generate mother plants.

After 14 - 21 days from planting (DAP), all the emerged plants had 5 - 8 leaves per plant. Three leaves, one each from the top, middle and bottom were picked from each plant and screened for the presence of potato viruses, namely PVS, PVX, PVY, PLRV, PVM and PVA using Double Antibody Sandwich ELISA kit (DAS-ELISA). The virus-free mother plants were retained, from which explants were obtained. The diseased mother plants were uprooted using a pair of forceps and destroyed by inceneration.

After four weeks, when the plants were approximately $20-30 \mathrm{~cm}$ tall, with 4 - 8 nodes, they were cut from the shoot bases using sterile surgical blades into individual shoots measuring approximately $20-28 \mathrm{~cm}$ tall. The large leaves were 
trimmed off and the nodal explants put in a flat bottomed cornical flask of $1000 \mathrm{ml}$ capacity. They were washed under running tap-water, supplemented with 5 drops of sodium stearate (liquid soap) for 40 minutes to remove the surface contaminants. The explants were then surface-sterilised under a laminar flow hood by immersing them in $70 \%$ ethanol for five seconds. They were further immersed in $14 \%$ sodium hypochlorite solution (JIK), supplemented with three drops of Tween-20 for two minutes. The explants were washed with autoclaved distilled water, three times, at an interval of five minutes, to remove residual JIK.

The disinfected materials were placed on sterilised cut pieces of paper, ready for inoculation onto the media. The explants with more than one node were cut into single nodes and initiated in glass autoclavable test tubes ( $14 \mathrm{~cm}$ height $\mathrm{x} 2$ $\mathrm{cm}$ diameter), containing MS (Murashige and Skoog, 1962) basal media to generate experimental plantlets. After inoculation onto the MS media, the cultured explants were transferred to a growth room at 16 hour photoperiod at $18{ }^{\circ} \mathrm{C}$, under approximately 1000 lux light intensity. The plantlets were micro-propagated after 3 4 weeks to increase the number of experimental plantlets.

Four weeks after the last sub-culture level on MS media, the plantlets were ready for excision and transfer to different hormonal combinations/treatments. Hormonal combinations N1-N4 and B1B4, composed of MS alone and MS media, supplemented with different concentrations of Giberrellic acid $\left(\mathrm{GA}_{3}\right)$, Benzyl amino purine (BAP) and Napthalene acetic acid (NAA) were formulated by adding different concentrations of growth regulators into the basal MS media. Treatment N1 was composed of MS alone), $\mathrm{N} 2$ of MS+3 mg $\mathrm{l}^{-1} \mathrm{GA}_{3}+0.005 \mathrm{mg} \mathrm{l}^{-1} \mathrm{NAA}, \mathrm{N} 3$ of $\mathrm{MS}+4$ $\mathrm{mg} \mathrm{l}^{-1} \mathrm{GA}_{3}+0.01 \mathrm{mg} \mathrm{l}^{-1} \mathrm{NAA}$ ) and $\mathrm{N} 4$, $\mathrm{MS}+5 \mathrm{mg} \mathrm{l}^{-1} \mathrm{GA}_{3}+0.02 \mathrm{mg} \mathrm{l}^{-1}$ NAA. B1 was composed of MS alone, B2, MS + $3 \mathrm{mg} \mathrm{l}^{-1} \mathrm{GA}_{3}+1.5 \mathrm{mg} \mathrm{l}^{-1} \mathrm{BAP}, \mathrm{B} 3, \mathrm{MS}+4$ $\mathrm{mg} \mathrm{l}^{-1} \mathrm{GA}_{3}+2.0 \mathrm{mg} \mathrm{l}^{-1} \mathrm{BAP}$ and $\mathrm{B} 4, \mathrm{MS}+5$ $\mathrm{mg} \mathrm{l}^{-1} \mathrm{GA}_{3}+2.5 \mathrm{mg} \mathrm{l}^{-1} \mathrm{BAP}$.

The $\mathrm{pH}$ of the MS media was adjusted to 5.8 , solidified with $6 \mathrm{~g} \mathrm{l}^{-1}$ agar and autoclaved at $121{ }^{\circ} \mathrm{C}$ for 20 minutes. When the temperature of the media decreased to about $50{ }^{\circ} \mathrm{C}$, the growth regulators were added by filter-sterilisation and mixed thoroughly by handshaking under a lamina flow hood. About $8-10 \mathrm{ml}$ of the media were dispensed in glass test tubes ( $14 \mathrm{~cm}$ height $\mathrm{x} 2 \mathrm{~cm}$ diameter) and left to cool. Ten shoot tips were subcultured to each of the hormonal combinations, in 3 replications. The experiment was laid out in a completely randomised design (CRD). The experiment was repeated three times.

Four weeks after transferring the plantlets onto different hormonal combinations, data were collected on shoot height, number of shoots, number of buds, number of visible primary roots and number of nodes. The data were subjected to analysis of variance (ANOVA), using GenStat Statistical Package, $13^{\text {th }}$ Edition. The significant means were compared using the Least Significant Difference at $5 \%$ level of probability.

\section{Results}

Number of shoots per plant, variety, hormonal combinations and the interaction showed no significant effect $(\mathrm{P}>0.05)$. However, shoot height, and number of buds, roots, leaves and nodes were significantly different for varieties and hormonal combinations. 
Variety, hormonal combinations and their interaction had a high significant effect on potato plantlet shoot height $(\mathrm{P}<0.001)$. The tallest plantlets were produced by Victoria and hormonal combinations $\mathrm{N} 2-\mathrm{N} 4$ had the highest overall effect on shoot height, though not significantly different from each other. However, they were different from the rest of the combinations.

Hormonal combination N4 produced the tallest plantlets for Kachpot 1 and Victoria; yet N3 produced the tallest plantlet for Kinigi. The shortest plantlets were produced by hormonal combination B2 for both Katchpot 1 and Victoria. In each variety, N1 and B1 did not differ from each other on shoot height (Table 1).

Interactions among variety, hormonal combinations and their interaction were highly significant $(\mathrm{P}<0.001)$ for number of buds per plant (Table 2). The highest number of buds was produced by Victoria, while the lowest by Kinigi. Hormonal combination N3 had the highest overall effect on bud initiation, closely followed by $\mathrm{N} 2$.

Hormonal combination N2 initiated the highest number of buds for Kachpot 1, closely followed by hormonal combination N3. The lowest number of buds was initiated by hormonal combination B2. Hormonal combination N4 initiated the highest number of buds for Victoria but did not differ significantly from $\mathrm{N} 3$ and N2. The lowest number of buds was initiated by hormonal combination B3. Hormonal combinations $\mathrm{N} 2$ and $\mathrm{N} 3$ initiated the highest number of buds for Kinigi. They were however, not significantly different from N4. The lowest number was initiated by B3. In each variety, $\mathrm{N} 1$ did not differ from $\mathrm{B} 1$ on the number of buds initiated (Table 2).
Results regarding the hormonal combinations, varieties and their interaction indicated a very high statistical significance $(\mathrm{P}<0.001)$ on root development (Table 3). Kachpot 1 produced a significantly higher number of roots while Victoria and Kinigi did not significantly differ from each other.

Table 1. Shoot height of potato plantlet arising from the interaction between varietal and hormonal treatments

\begin{tabular}{lrrr}
\hline Treatment & \multicolumn{3}{c}{ Shoot height $(\mathrm{cm})$} \\
\cline { 2 - 4 } & Kachpot & Kinigi & Victoria \\
\hline N1 & 5.81 & 3.74 & 5.96 \\
N2 & 6.14 & 6.80 & 6.63 \\
N3 & 6.17 & 7.38 & 7.05 \\
N4 & 6.76 & 6.00 & 7.19 \\
B1 & 5.81 & 3.74 & 5.96 \\
B2 & 3.19 & 3.59 & 4.31 \\
B3 & 3.37 & 2.65 & 4.57 \\
B4 & 3.25 & 2.59 & 4.38 \\
& & & \\
LSD & & 0.57 & \\
\hline
\end{tabular}

Table 2. Number of buds on potato plantlet arising from the interaction between varietal and hormonal treatments

\begin{tabular}{lccc}
\hline Treatment & \multicolumn{3}{c}{ Buds per plant } \\
\cline { 2 - 4 } & Kachpot & Kinigi & Victoria \\
\hline $\mathrm{N} 1$ & 4.72 & 3.02 & 4.93 \\
$\mathrm{~N} 2$ & 5.36 & 4.32 & 5.70 \\
$\mathrm{~N} 3$ & 5.27 & 4.32 & 5.76 \\
$\mathrm{~N} 4$ & 4.79 & 4.08 & 5.88 \\
$\mathrm{~B} 1$ & 4.72 & 3.02 & 4.93 \\
$\mathrm{~B} 2$ & 2.32 & 1.97 & 3.07 \\
$\mathrm{~B} 3$ & 2.42 & 1.68 & 2.99 \\
$\mathrm{~B} 4$ & 2.50 & 1.84 & 3.37 \\
& & & \\
LSD $_{0.05}$ & & 0.39 & \\
\hline
\end{tabular}


Hormonal combination N4 had the highest overall impact on root development. This was followed by hormonal combinations $\mathrm{N} 2$ and N3. Hormonal combination N4 initiated the highest number of roots for Victoria. The lowest number was induced by hormonal combination B4.

Hormonal combination N2 induced the highest number of roots for Kachpot 1 , though it did not differ from N3 and N4. The lowest number was induced by B4. Hormonal combination N2 induced the highest number of roots for Kinigi though not statistically different from N3 and N4. B4 had the least effect on root initiation and development though not statistically different from B2 for Kinigi (Table 3).

The ANOVA table showed that there was a very high statistical significance between variety, hormonal combinations and their interaction on the development of leaves $(\mathrm{P}<0.01)$. The highest number of leaves was noticed on Kachpot 1, followed by Victoria while Kinigi produced the least number of leaves. Hormonal combination $\mathrm{N} 1$ and $\mathrm{B} 1$ had the greatest

Table 3. Number of roots on potato plantlet arising from the interaction between varietal and hormonal treatments

\begin{tabular}{lccc}
\hline Treatment & \multicolumn{3}{c}{ Roots per plant } \\
\cline { 2 - 4 } & Kachpot & Kinigi & Victoria \\
\hline N1 & 4.68 & 4.28 & 3.56 \\
N2 & 6.28 & 4.96 & 5.14 \\
N3 & 5.83 & 4.87 & 5.27 \\
N4 & 5.90 & 4.94 & 5.76 \\
B1 & 4.68 & 4.28 & 3.56 \\
B2 & 0.59 & 0.37 & 0.24 \\
B3 & 1.53 & 0.84 & 1.19 \\
B4 & 0.34 & 0.10 & 0.19 \\
& & & \\
LSD & & 0.46 & \\
\hline
\end{tabular}

impact on the development of leaves. The least impact was produced by hormonal combinations B3 (Table 4).

Hormonal combination $\mathrm{N} 1$ and $\mathrm{B} 1$ induced the highest number of leaves in Victoria. This was followed by N3. The least number of leaves was induced by hormonal combinations B3 in Victoria. The highest number of leaves in Kachpot 1 was also induced by $\mathrm{N} 1$ and B1. This was followed by hormonal combination $\mathrm{N} 4$ that did not significantly differ from N2 and N3. The lowest number was induced by B2 for Kachpot 1 . Hormonal combination N2 induced the highest number of leaves in Kinigi though it was not significantly different from N1, B1 and N3. B3 induced the least number of leaves in Kinigi (Table 4).

For both varieties, hormonal combination and their interaction were highly significant $(\mathrm{P}<0.001)$. Kachpot 1 and Victoria had similar number of nodes produced; while Kinigi produced the least number of nodes. Hormonal combination $\mathrm{N} 3$ induced the highest number of nodes

Table 4. Number of leaves on potato plantlet arising from the interaction between varietal and hormonal treatments

\begin{tabular}{lccr}
\hline Treatment & \multicolumn{3}{c}{ Leaves per plant } \\
\cline { 2 - 4 } & Kachpot & Kinigi & Victoria \\
\hline $\mathrm{N} 1$ & 8.71 & 5.03 & 7.14 \\
$\mathrm{~N} 2$ & 6.64 & 5.18 & 6.23 \\
$\mathrm{~N} 3$ & 6.63 & 5.07 & 6.51 \\
$\mathrm{~N} 4$ & 6.70 & 4.63 & 6.43 \\
$\mathrm{~B} 1$ & 8.71 & 5.03 & 7.14 \\
$\mathrm{~B} 2$ & 4.84 & 3.70 & 5.22 \\
$\mathrm{~B} 3$ & 4.89 & 3.40 & 4.82 \\
$\mathrm{~B} 4$ & 4.87 & 3.51 & 4.87 \\
& & & \\
LSD $_{0.05}$ & 0.45 & & \\
\hline
\end{tabular}


Table 5. Number of nodes on potato plantlet arising from the interaction between varietal and hormonal treatments

\begin{tabular}{lccc}
\hline \multirow{2}{*}{ Treatment } & \multicolumn{3}{c}{ Nodes per plant } \\
\cline { 2 - 4 } & Kachpot & Kinigi & Victoria \\
\hline $\mathrm{N} 1$ & 8.14 & 4.89 & 6.51 \\
$\mathrm{~N} 2$ & 7.17 & 6.57 & 7.43 \\
$\mathrm{~N} 3$ & 7.19 & 6.42 & 7.72 \\
$\mathrm{~N} 4$ & 7.11 & 6.41 & 7.66 \\
$\mathrm{~B} 1$ & 8.14 & 4.89 & 6.51 \\
$\mathrm{~B} 2$ & 5.24 & 5.04 & 5.37 \\
$\mathrm{~B} 3$ & 5.01 & 4.46 & 5.28 \\
$\mathrm{~B} 4$ & 4.86 & 4.53 & 5.14 \\
LSD $_{0.05}$ & & 0.41 & \\
\hline
\end{tabular}

closely followed by N2 and N4 with the same mean.

B4 induced the lowest overall number of nodes (Table 5). Hormonal combination $\mathrm{N} 1$ and B1 produced a significantly higher number of nodes in Kachpot 1. This was followed by hormonal combination N3. However, N2, N3 and N4 did not significantly differ from each other. The lowest number of buds was initiated by B4 in Kachpot 1. Hormonal combination $\mathrm{N} 3$ initiated the highest number of nodes in Victoria though it did not significantly differ from $\mathrm{N} 2$ and N4. The lowest number was induced by B4. N2 induced the highest number of nodes in Kinigi though it did not significantly differ from $\mathrm{N} 3$ and N4. The least number of nodes was initiated by hormonal combination B3. B3 however did not significantly differ from hormonal combination B4 (Table 5).

\section{Discussion}

It is often necessary to alter the composition and or concentration of growth regulators in the culture medium depending on the genotype, origin of the explants and culture conditions. It is known that organogenesis is highly dependent on the interaction between naturally occurring endogenous growth hormones and exogenous growth regulators added to the culture medium (Muhammad and Hakoomat, 2004). Regeneration through direct organogenesis (directly from organs) gives plants that do not exhibit somaclonal variation and are true to type. A combination of $\mathrm{GA}_{3}$ and NAA increased the shoot height though there were variations among the cultivars. These results are similar to those of Badoni and Chauhan (2009) who reported that a combination of $\mathrm{GA}_{3}$ and NAA showed best results for improving all the growth parameters. Abdul et al. (2003) and Zaman et al. (2001) obtained maximum plant height $(9 \mathrm{~cm})$ when NAA alone was added to the medium at $0.15 \mathrm{mg} \mathrm{l}^{-1}$. Maximum shoot height was also obtained by Rabbani et al. (2001) and Ahmed et al. (1993) when a high concentration of $\mathrm{GA}_{3}$ at $4 \mathrm{mg} \mathrm{l}^{-1}$ and $4.5 \mathrm{mg} \mathrm{l}^{-1}$ respectively. $\mathrm{GA}_{3}$ is physiologically involved in cell elongation in plants (Levitt, 1974). This explains the increased shoot height for hormonal combinations $\mathrm{N} 2$ to $\mathrm{N} 4$ in the present study.

The number of shoots did not differ significantly $(\mathrm{P}<0.001)$ across all the hormonal combinations for all the varieties. However, several researchers have reported that use of BAP alone has been the most effective growth regulator in stimulating organogenesis in different solanum tuberosum cultivars (Abdul et al., 2003; Molla et al., 2011). The combination of $\mathrm{GA}_{3}$ and BAP did not result in increased number of shoots. This could be due to the effect of hormonal combination (antagonistic) or the concentrations used. The results of this 
study suggest that BAP should be used alone or the concentrations of the hormonal combinations be lowered in order to induce multiple shoots.

Though there are differences among the cultivars, a combination of $\mathrm{GA}_{3}$ and NAA resulted in more number of roots. The results on root development are in agreement with those of Vinterhalter $e t$ al. (1997) and Khadiga et al. (2009) who reported that potato is an easy to root specie and may not need exogenous hormones for rooting. The plantlets in all MS supplemented with $\mathrm{GA}_{3}$ and $\mathrm{BAP}$ (B1 - B4) developed very few roots. This can be attributed to the fact that BAP at a higher concentration inhibits root development and promotes shoot development. All the hormonal combinations did not result in increased number of leaves. Hormonal combination N1 may result in increased photosynthetic ability of the plantlets due the high number of leaves.

Zaman et al. (2001) obtained the highest number of leaves when a higher concentration of auxin alone was used. The reduced number of leaves was as a result of low auxin concentration and probably a combination of low auxin and high $\mathrm{GA}_{3}$ concentration that resulted in narrow and elongated shoots.

The MS media, when supplemented with $\mathrm{GA}_{3}$ and NAA resulted in increased number of nodes for Kinigi and Victoria (Table 5). These results are similar to those obtained by Miller et al. (1985) who reported an increased number of nodes at a higher concentration of $\mathrm{GA}_{3}$ along with NAA (1.0 $\left.\mathrm{mg} \mathrm{l}^{-1}\right)$. However, when Rabbani et al. (2001) used a higher concentration of $\mathrm{GA}_{3}$ alone, it did not result in increased number of nodes. Moreover, Zaman et al. (2001) obtained a higher number of nodes at a higher concentration of auxins alone. When MS was supplemented with a combination of $\mathrm{GA}_{3}$ and BAP, the number of nodes did not increase. In view of these results and those obtained by Anoop and Chauhan (2009) and Miller et al. (2009), higher concentration of $\mathrm{GA}_{3}$ should be supplemented with NAA.

The effect of hormonal combinations on the multiplication of tissue culture plantlets varied from variety to variety (Tables 1-5). Hormonal combination N2 increased the number of in vitro plantlets for Kachpot 1 variety due the increased number the initiated buds. Hormonal combination N4 increased the number of buds, shoot height and number of nodes for Victoria. Hormonal combination N3 increased the plant shoot height, buds and number of nodes for Kinigi.

In view of the results obtained in the present study, the use of $\mathrm{GA}_{3}$ and NAA is recommended. This combination will help increase the rate of multiplication in shoot tip culture by increasing the plantlet height, the number of nodes and buds on the plantlets obtained. The concentrations of $\mathrm{GA}_{3}$ and BAP used in this study favoured callus development and therefore they should be lowered. In addition, NAA should be included in the hormonal combination and a proper balance between BAP and NAA be observed. Though callus proliferation from the tissues of most plants is thought to require the presence of both auxin and cytokinins in the growth medium, Yousef et al. (1997) obtained callus-free potato plantlets when low concentrations of BAP and NAA were used.

\section{Acknowledgement}

Uganda National Council of Science and Technology (UNCST) World Bank for 
their funding of this research through the Milleniun Science Initiative (MSI) funded this research.

\section{References}

Abdul, G., Shah, G.B. and Waseem, K. 2003. In vitro response of potato (Solanum tuberosum L.) to various growth regulators. Biotechnology 2(3): -191-197.

Ahmed, S., Bhatti, M., Hidayatullah and Qurashi, A. 1993. An improved method for in vitromultiplication of potato. Advances in Plant Tissue Culture, Pakistan 61-5.

Badoni, A. and Chauhan, J.S. 2010. Conventional vis-à-vis Biotechnological methods of propagation in potato: A review. Stem Cell 1: 1-6.

Badoni, A. and Chauhan, J.S. 2009. Effects of growth regulators on meristem-tipdevelopment and in vitro multiplication of potato cultivar 'Kufri Himalini'. Nature and Science 7 (9): 31 - 34. African Journal of Biotechnology 11 (17):3993-3999.

FAO. 2007. Home page. Available on the: htpp://www.fao.org

Ferris, R.S.B., Okoboi, G., Crissman, C., Ewell. P. and Lemaga, B. 2001. Study of performance and growth prospects for Irish potatoes as a component for development of strategic exports in Uganda, report prepared by IITAFOODNET, CIP, PRAPACE.

Khadiga, G., Elaleem, A., Rasheid, S. M., and Mutasim, M. K. 2009. Effect of cultivar and growth regulator on in vitro micropropagation of potato (Solanum tuberosum L.). AmericanEurasian Journal of Sustainable Agriculture 3(3): 487-492.
Mahmoud, O. 2006. Utilisation of tissue culture techniques in a seed potato tuber production scheme. $\mathrm{PhD}$ Thesis, Wageningen University, Netherlands.

Miller, P.R., Amirourche, L., Stuchbury, T. and Mathew, S. 1985. The use of plant growth regulators in micro-propagation of slow growing potato cultivars. Potato Research 28:479-86.

Molitor, H.D., Fischer, M. and Popadopoulos, A. P. 1999. Effect of several parameters on the growth of Chrysanthemum stock plants in aeroponics. Volume I. Acta Horticulture 481:179-186.

Molla, M.M.H., Nasiruddin, K.M., AlAmin, M., Khanam, D. and Salam, M.A. 2011. Effects of growth regulators on direct regeneration of potato. International Conference on Environment and Industrial Innovation. Volume 12.

Muhammad, A.A. and Hakoomat, A. 2004. Effect of culture medium on direct organogenesis from different explants of various potato genotypes. Biotechnology 3 (2):187-193.

Murashige, T. and Skoog, F. 1962. A revised medium for rapid growth and bioassays with tobacco tissue culture. Physiologia Plant 15:473-497.

Rabbani, A., Askari, B., Askari, A.N., Akhlar, A.N., Bhatti, M. and Quraishi, A. 2001. Effect of growth regulators on multiplication of potato. International Journal of Agriculture and Biology 03 (2):181-182.

Ritter, E., Angulo, B., Riga, P., Herran, C., Relloso, J. and San Jose, M. 2001. Comparison of hydroponic and aeroponics cultivation systems for the production of potato mini-tubers. Potato Research 44:127-135. 
Vinterhalter, D., Vinterhalter, B. and Yoesef, A.A.R., Suwwan, M.A., Musa, Calovic. 1997. The relationship A.M. and Abu-Qaoud, H.A. 1997. In between sucrose and cytokinins in the vitro culture and microtuberization of regulation of growth and branching in spunta potato (Solanum tuberosum potato cv. Desiree shoot cultures. Acta $\quad$ L.). Dirasat Agricultural Sciences Horticulturae 462:319-323. 24: 173-181. 